\title{
Left ventricular aneurysm
}

\author{
C. H. BECKERLING, B. H. G IB B, H. G. H. HOU GH T ON, A N D \\ B. T. LE ROUX \\ From the Thoracic Surgical and Cardiological Units of the University of Natal and the \\ King George V Jubilee Hospital, Durban
}

\begin{abstract}
Left ventricular aneurysm in African patients is most often luetic; the only other common left ventricular aneurysm in African patients is agnogenic and not a complication of coronary artery disease. The management of a left ventricular aneurysm by surgical excision with cardiorespiratory bypass in an African patient is described. The literature which relates to left ventricular aneurysm in African patients is briefly reviewed.
\end{abstract}

Ventricular aneurysms are rare, and most complicate myocardial infarction. Coronary artery occlusion is rare in the African; there is only one report of ventricular aneurysm which may have followed myocardial infarction in an African patient, and in this case there was the possibility that the infarct was the complication of coronary embolism (Lurie, 1960). Ventricular aneurysm in the African is most often a complication of syphilis (Brink and Barnard, 1954; Jacobs and Elliott, 1955), an aetiological emphasis different from that in patients of Caucasian stock, among whom ventricular aneurysm is usually the consequence of coronary artery occlusion and myocardial infarction. Cardiac aneurysm in the African has also been reported as complicating bacterial endocarditis (Pirani, 1943), tuberculosis (Brink and Barnard, 1954), malaria (Macfie and Ingram, 1920), Chagas disease, and rheumatic myocarditis (Crawford, 1943). Stab wounds of the heart, either homicidal or surgical (for example, for transventricular mitral valvulotomy), are rarely complicated by aneurysm. Errors in development may result in a variety of unusual aneurysms. Robertson and Jackson (1960) and Abrahams, Barton, Cockshott, Edington, and Weaver (1962) have described a variety of sub-valvular aneurysms in the left ventricle in patients in Nigeria. These aneurysms develop in relation to the annulus of either the aortic or mitral valves immediately below which the orifice of origin of the aneurysm may be situated; the aneurysmal cavity encircles or courses within the fibrous ring of either of the valves mentioned, and ultimately presents through the wall of the left ventricle or extends into the interventricular septum. The patients described with this variety of aneurysm have been young
(6 to 37 years of age), and they present with congestive cardiac failure, the consequence of aortic or mitral incompetence, itself related to stretching of the valve ring. There is also a congenital diverticulum which may extend from the apex of the ventricle to herniate through the diaphragm and present as a pulsating mass in the epigastrium (Skapinker, 1951). Ventricular muscle bundles may themselves be the site of abnormal development and give rise to aneurysms which present on the antero-lateral surface of the left ventricle (Clearkin and Bunjé, 1955; Stroud, 1945). These aneurysms are unrelated to the valve rings or to the apex of the ventricle. When a coronary artery has an anomalous origin from the pulmonary artery inadequate myocardial perfusion can occur, and a sequel of this may be myocardial infarction and the formation of an aneurysm (Bland, White, and Garland, 1933). Bayer (1940) described a variety of subpericardial cysts lined by ciliated columnar epithelium which may present as a ventricular aneurysm. In most African patients who have left ventricular aneurysm unrelated to syphilis a cause has not been ascertained.

The purpose of this paper is to describe the surgical management of a left ventricular aneurysm in an African patient in whom the cause for the aneurysm was not found. Schrire and Barnard (1963) have reported a similar case. Most other examples of idiopathic left ventricular aneurysm in African patients have been reports of necropsy examination.

\section{CASE REPORT}

An African man of 26 years was radiographed, not because of symptoms but because he was about to 
undertake particular employment. The radiographs showed (Fig. 1) an anomaly of the left heart border. Clinical examination was uninformative apart from the presence of a heaving cardiac impulse in the third, fourth, and fifth intercostal spaces in the left anterior axillary line, together with a short ejection systolic murmur in this area. A strip of the electrocardiogram is shown (Fig. 2); in this there is a $Q$ wave of $0.05 \mathrm{sec}$. in lead $\mathrm{I}$, with small $\mathrm{Q}$ waves in $\underset{\overrightarrow{\mathrm{s}}}{\overrightarrow{\vec{g}}}$ V5 and V6, a deep $S$ wave in V1 $(22 \mathrm{~mm}$.), and inversion of the $\mathrm{T}$ wave in the left ventricular leads. 듬 One interpretation of this electrocardiogram was that $\overline{\bar{c}}$ there was an anterior myocardial infarct with left $\vec{\varnothing}$ ventricular hypertrophy. When it was subsequently $\cong$ shown that there was a defect in the anterior wall of $ळ$ the left ventricle communicating with an aneurysmal $\vec{\circ}$

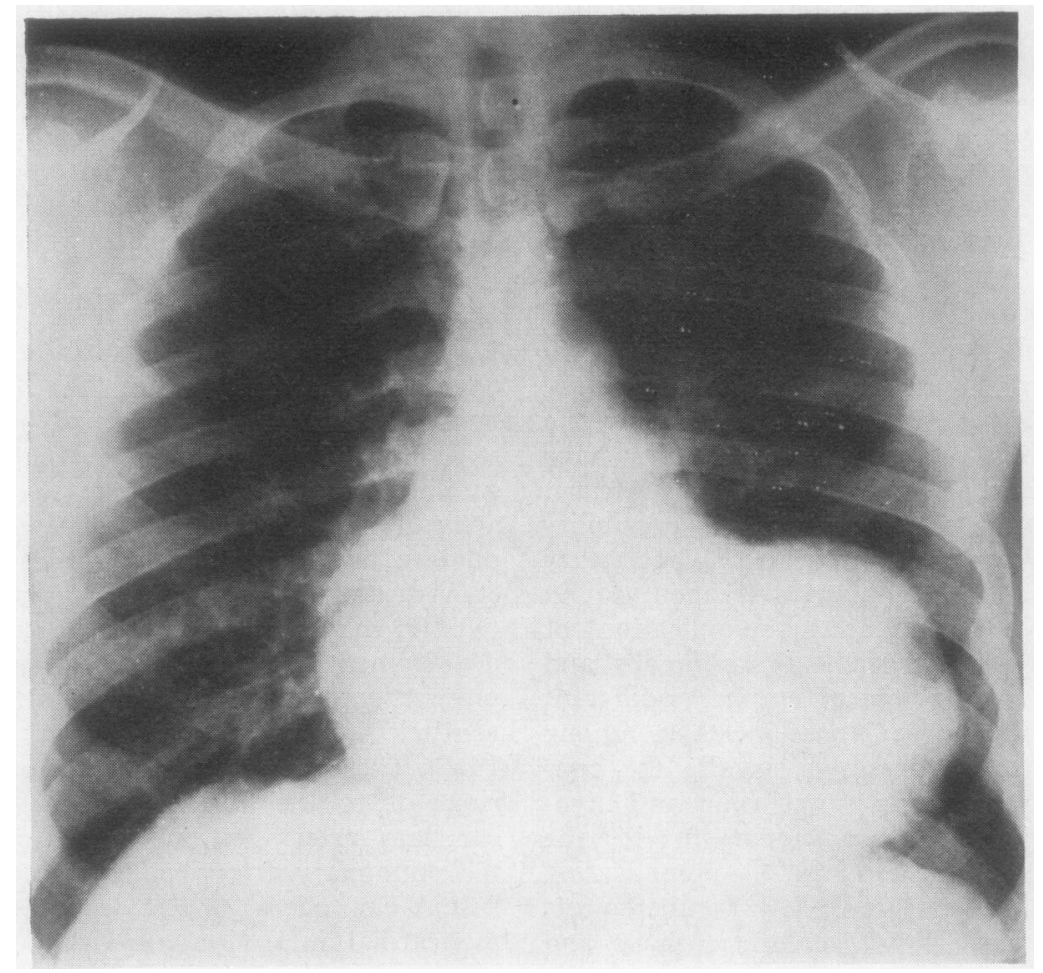

FIG. 1. Postero-anterior chest radiograph in which the left ventricular aneurysm is clearly seen.

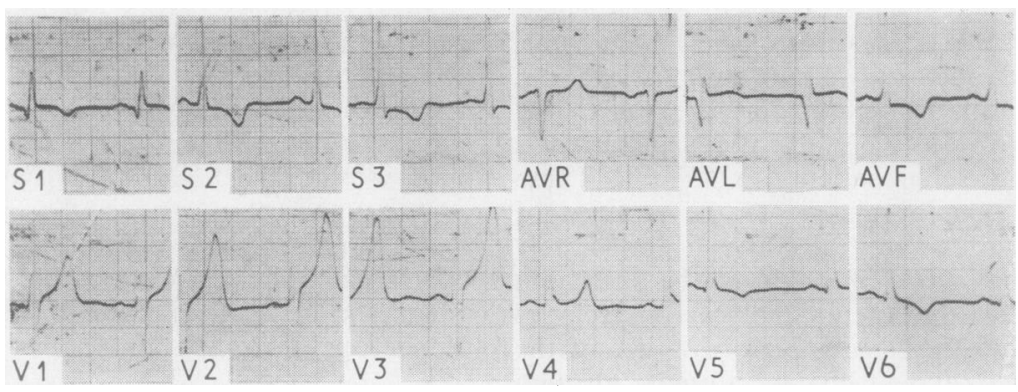

FIG. 2. Pre-operative electrocardiogram in which is seen a $Q$ wave of $0.05 \mathrm{sec}$. in lead $I$, small $Q$ waves in $V 5$ and $V 6$, a deep $S$ wave in $V 1$, and $T$-wave inversion in the left ventricular leads. 
sac it was thought that the electrocardiographic changes were compatible with this finding, and the original interpretation was discounted.

Left ventricular angiography showed an aneurysmal sac with a narrow neck in the upper aspect of the left ventricle, close to the mitral valve. The radiographic quality of the angiogram does not warrant reproduction. Serological tests for syphilis were negative.

With cardiorespiratory bypass and moderate hypothermia the aneurysm was resected. The approach was through a left thoracotomy; venous drainage for bypass was from the left femoral vein, subsequently supplemented by a venous catheter in the right ventricular outflow. Arterial return was to the left femoral artery and the temperature was allowed to fall to $28^{\circ} \mathrm{C}$. in order to induce ventricular fibrillation. The aneurysm was densely adherent to the pericardium, which was not mobilized in relation to the aneurysm. The aneurysm was widely opened and a considerable quantity of clot was evacuated. The communication with the left ventricle was $1.5 \mathrm{~cm}$. in diameter. The left ventricle was vented and the neck of the aneurysm was closed with a series of interrupted silk sutures; thereafter the aneurysmal sac was trimmed and used to cover the ventricular closure in two layers. Convalescence was uncomplicated apart from the need to aspirate a left pleural effusion. Histological examination of that part of the aneurysm resected showed fibrous tissue and areas of chronic inflammation.

Surgical management was undertaken in this patient despite the absence of symptoms because of the strong likelihood of complications from the aneurysm. Patients with left ventricular aneurysm, the complication of myocardial infarc- tion, uncommonly die because of rupture of the aneurysm, probably because they die in cardias failure or from further episodes of coronary artery occlusion before the aneurysm ruptures. Patients with left ventricular aneurysm, complicating syphilis, or one of the less usual causes of this rare disease, and patients with idiopathic aneurysm of the left ventricle commonly die from rupture of the aneurysm, and death in these circumstances need not have been preceded by symptoms related to the aneurysm (Jacobs and Elliot, 1955).

\section{REFERENCES}

Abrahams, D. G., Barton, C. J., Cockshott, W. P., Edington, G. M. and Weaver, E. J. M. (1962). Annular subvalvular left ventricular aneurysms. Quart. J. Med., 31, 345.

Bayer, J. (1940). Cysten und Divertikel des Herzens. Virchows Arch. path. Anat., 306, 43. Quoted by Hudson, R. E. B., Cardiovascular Pathology, vol. 2, p. 1745 . Edward Arnold, London (1965).

Bland, E. F., White, P. D., and Garland, J. (1933). Congenital anomalies of the coronary arteries. Amer. Heart J., 8, 787.

Brink, A. J., and Barnard, P. J. (1954). Syphilitic aneurysm of the left ventricle with calcification and ossification. $S$. Afr. med. $J, 28$, 476.

Clearkin, K. P., and Bunjé, H. (1955). Rare cardiac aneurysm in a young adult. Thorax, 10, 42.

Crawford, J. H. (1943). Aneurysm of the heart. Arch. intern. Med. 71,502 .

Jacobs, H. D., and Elliott, G. A. (1955). Cardiac ventricular aneurysm in South Africa. Acta med., scand., 306, p. 84.

Lurie, A. O. (1960). Left ventricular aneurysm in the African. Brit. Heart J., 22, 181.

Macfie, J. W. S., and Ingram, A. (1920). Three cases of cardiac aneurysm in native boys of the Gold Coast. Ann. trop. Med. Parasit., 14, 147.

Pirani, C. L. (1943). Erosive mycotic aneurysm of the heart with rupture. Arch. Path., 36, 579.

Robertson, J. H., and Jackson, J. G. (1960). Cardiac aneurysms in Nigeria. J. Path. Bact., 80, 101.

Schrire, V., and Barnard, C. N. (1963). The surgical cure of a cardiac aneurysm of unknown cause. J. cardiovasc. Surg. (Torino), 4, 5.

Skapinker, S. (1951). Diverticulum of the left ventricle of the heart. Arch. Surg., 63, 629.

Stroud, W. D. (1945). The Diagnosis and Treatment of Cardiovascular Disease, 3rd ed., Vol. 1, p. 854. Davis, Philadelphia. 